\title{
The hidden consequences of burnout in pediatric radiology
}

\author{
George A. Taylor ${ }^{1,2} \cdot$ Rama S. Ayyala ${ }^{3}$ \\ Received: 5 February 2019 / Accepted: 17 February 2019 / Published online: 8 May 2018 \\ (C) Springer-Verlag GmbH Germany, part of Springer Nature 2019
}

\section{Introduction}

This issue of Pediatric Radiology contains the results of a recent survey on burnout that was conducted by the Society for Pediatric Radiology [1]. The manuscript discusses stressors associated with burnout within our specialty. As part of the survey, we asked respondents to contribute any additional free-text comments regarding the topic. These comments, as was the entire survey, were anonymous.

\section{Selected anonymous comments}

- "I feel like quitting every day and getting out of medicine."

- "I would consider myself clinically depressed but feel there's too much professional stigma associated with seeking help to fully address it."

- "Forget about happiness. If I didn’t actually like radiology and needed to make a living I would be long gone."

- "Burned out. Attempted suicide 9 years ago."

\section{The problem and its consequences}

Burnout is real, and as these comments show, it can have real consequences to the pediatric radiologist, to his or her

Rama S. Ayyala

rayyala@gmail.com

1 Harvard Medical School, Boston, MA, USA

2 Department of Radiology, Boston Children's Hospital, Boston, MA, USA

3 Department of Diagnostic Imaging, Rhode Island Hospital - Hasbro Children's Hospital, Warren Alpert Medical School of Brown University, 593 Eddy St., Providence, RI 02903, USA institution, and to society. Our specialty is relatively small, and the pipeline of future pediatric radiologists might be declining [2]. As a result, it is even more important to address burnout and the hidden mental health consequences early and assertively. If we do nothing, the specialty loses an important opportunity to make a course correction and set things right before the situation worsens.

What we seem to be experiencing in pediatric radiology is a microcosm of trends in the practice of medicine as a whole. The Massachusetts Medical Society recently published the results of the 2018 Survey of America's Physicians: Practice Patterns and Perspectives [3]. It calls burnout a public health crisis, with one of its primary negative impacts being on physician mental health. Another recent national survey of more than 15,000 physicians from 29 specialties revealed that $15 \%$ of U.S. physicians are depressed and contemplating suicide [4]. An even more concerning finding was that $64 \%$ of depressed respondents said they had no plans to seek help, nor had they sought help in the past for depression or burnout. In addition, survey comments suggest that some physicians are retiring earlier because of burnout or depression.

There is evidence that burnout and depression are overlapping phenomena, and that the distinction between burnout and depression is unclear and conceptually fragile [5]. The negative consequences of burnout and depression on physician performance are important. In a population-based survey of U.S. physicians performed in 2014, Tawfik et al. [6] showed that physicians reporting errors were significantly more likely to have symptoms of burnout ( $77.6 \%$ vs. $51.5 \%$ ), fatigue ( $46.6 \%$ vs. $31.2 \%)$, and recent suicidal ideation ( $12.7 \%$ vs. $5.8 \%$ ). For every 1-point increase in burnout (on a 7-point scale). There is an associated $30-40 \%$ increased likelihood that physicians will reduce their work hours in the next 2 years [7]. It is estimated that burnout contributes to a $1 \%$ reduction in physicians' professional work effort. This reduction coupled with other outcomes of burnout such as early retirement or leaving the profession altogether could have serious consequences to medicine in general, and specifically to our specialty. 


\section{Going forward}

Solutions need to go far beyond offering wellness classes or helping doctors become more resilient. "You can't yoga yourself out of burnout," observed Robert McLean, president-elect of the American College of Physicians [8]. Others have suggested that hospital systems need to obtain input from frontline workers before making decisions and implementing policies that affect how they do their jobs [8].

Physicians face stigma and professional obstacles to seeking appropriate care and treatment for burnout and related mental health concerns. Radiology departments and institutions should take deliberate steps to facilitate appropriate treatment and support without stigma or unnecessary constraints on physicians' ability to practice [3].

By bringing these problems forward, we hope to facilitate the discussion about mental illness among physicians. For those who are experiencing worsening depression or suicidal ideation, it is important to feel safe in seeking help without the accompanying stigma. For those in leadership positions, several steps are important, including identifying institutional or community resources, creating a safe environment for the affected individual to seek help, re-dedicating oneself to departmental initiatives to mitigate burnout, and creating a path so that valuable members of a department can return to meaningful work.

\section{Compliance with ethical standards}

Conflicts of interest None

Publisher's note Springer Nature remains neutral with regard to jurisdictional claims in published maps and institutional affiliations.

\section{References}

1. Ayyala RS, Ahmed FS, Ruzal-Shapiro C, Taylor GA (2018) Prevalence of burnout among pediatric radiologists. J Am Coll Radiol. https://doi.org/10.1016/j.jacr.2018.08.016

2. Pfeifer CM (2018) Declining interest in pediatric radiology prompts a call to action. J Am Coll Radiol 15:490-492

3. Jha AK, Li KT, Williams MA et al (2018) A crisis in health care: a call to action on physician burnout. Massachusetts Medical Society. http://www.massmed.org/News-and-Publications/MMS-NewsReleases/Physician-Burnout-Report-2018/. Accessed 18 Jan 2019

4. Kane L (2019) Medscape national physician burnout, depression \& suicide report 2019. https://www.medscape.com/slideshow/2019lifestyle-burnout-depression-6011056?faf=1\#1. Accessed 18 Jan 2019

5. Bianchi R, Schonfeld IS, Laurent E (2015) Burnout-depression overlap: a review. Clin Psychol Rev 36:28-41

6. Tawfik DS, Profit J, Morgenthaler TI et al (2018) Physician burnout, well-being, and work unit safety grades in relationship to reported medical errors. Mayo Clin Proc 93:1571-1580

7. Shanafelt TD, Mungo M, Schmitgen J et al (2016) Longitudinal study evaluating the association between physician burnout and changes in professional work effort. Mayo Clin Proc 91:422-431

8. Bendix J (2019) The real reason docs burnout. Medical Economics http://www.medicaleconomics.com/business/real-reason-docs-burnout. Accessed 18 Jan 2019 